\title{
Psychological and medical problems in prevention and treatment of eating disorders among people with type 1 diabetes
}

\section{ABSTRACT}

Eating disorders have been recognized as a serious clinical problem in developing countries. They can also cause many mental and physical disorders in adolescents and young adults. A lot of patients with type 1 diabetes frequently manipulate with insulin doses in order to control their body weight. This phenomenon is known as diabulimia. Type 1 diabetes and eating disorders usually affect teenagers and young adults and can lead to serious health consequences. Very often they are not noticed by social environment. However, they may be recognized relatively early by a diabetologist, if he is aware of this possibility, basing on the patient's somatic symptoms. Due to the growing problem of eating disorders among people with type 1 diabetes we decided to look at this phenomenon and to draw attention to its characteristics, risk factors, ways of treatment and interventions in cases of suspecting diabulimia. (Clin Diabet 2016; 5, 1: 26-31)

Key words: eating disorders, diabulimia, type 1 diabetes

\section{Introduction}

Eating disorders have psychological background. They include specific disorders such as: anorexia nervosa or bulimia. They can also be of non-specific character

\footnotetext{
Address for correspondence:

mgr Agata Juruć

Katedra i Klinika Chorób Wewnętrznych i Diabetologii

Uniwersytet Medyczny im. Karola Marcinkowskiego, Poznań

e-mail: agatajuruc@wp.pl

Translation: GROY Translations

Clinical Diabetology 2016, 5, 1, 26-31

DOI: $10.5603 /$ DK.2016.0005

Received: 23.09.2015

Accepted: 07.12.2015
}

(rumination syndrome, night eating syndrome, compulsive overeating, attacks of overeating) [1]. Anorexia concerns eating disorders leading to intentional weight loss caused and supported by sick persons. These persons commonly suffer from high level of anxiety, low self-esteem, feeling of helplessness, lack of self-confidence, body dissatisfaction, and biased body image, and even fear of adulthood and puberty. Obsessive fear of gaining weight causes that patients constantly think about food and are deeply convinced that 'thin' figure is the key to success. Those persons are perfectionists and have high need for their successes and achievements validation. They concentrate on the external achievements such as education and gaining knowledge. At the same time they are very insecure and afraid of failing.

Risk factors of developing eating disorders include: genetic predispositions, neurobiological conditions and social and cultural expectations, e.g. ideal of thinness and social expectation of attractiveness that are mainly imposed on women. Familial factors also play substantial role in this field, especially strong subordination to the family system, parents overprotectiveness, unclear boundaries in relations between family members and child's role in the family system, denying conflicts and difficulties in solving them, behavioral inflexibility, fear of change, engaging a child in a conflict between parents and entering into coalition with one of them [2]. Currently, negative influence of media on shaping mainly youngsters body image is noticed, and its connection to lowered self-esteem in this age group.

According to the DSM-5 (American Psychiatric Association), criteria of diagnosing anorexia include [1]:

- refusing to maintain body weight at/or over the level of $85 \%$ of the minimal weight for a certain age and height or lack of proper weight gain in 
the growing period leading to keeping the body weight below $85 \%$ of the proper weight;

- experiencing intense fear of gaining weight or of obesity despite actually being visibly underweight;

- disturbed perception and experiencing one's weight and body shape, expressed by difficulties in seeing the influence of own opinion on the weight and body shape perception or denying the significance of low body weight.

In this classification 2 subtypes of anorexia are distinguished:

- the restricting type - no regular episodes of uncontrolled overeating and behaviour connected to removing food from the organism through vomiting and/or using laxatives;

- the binge-eating/purging type - noted regular episodes of uncontrolled overeating or behaviour connected to removing food from the organism through vomiting and/or using laxatives.

According to the ICD-10 classification, anorexia should be suspected when a person experiences strong fear of gaining weight even when being objectively underweight and also in a situation of decreasing body weight (lack of weight gain in children) reaching $15 \%$ of proper body weight or weight expected for certain age. While in adults, Body Mass Index (BMI) equal or lower than $17.5 \mathrm{~kg} / \mathrm{m}^{2}$ is taken into consideration. The BMI determines a ratio of body weight to height. This classification includes also endocrine disorders affecting pituitary-suprarenal axis and gonads. In women it is manifested by lack of menstruation, and in men - by drop of potency and interest in sex. Additionally, increased levels of growth hormone and cortisol are found as well as changes in metabolism of thyroid hormones and disturbances in insulin secretion. Attention is brought also to the fact that if the disorder begins before puberty then numerous phenomena related to puberty are delayed or inhibited (growth inhibition, lack of breasts development in girls or primary amenorrhea, and boys' reproductive organs remain in a state characteristic for children) [3].

Eating disorders were described for the first time in the $17^{\text {th }}$ century by Richardt Morton. It is estimated that annual incidence is $8-13$ cases per every 100 thousand persons, and the prevalence is $0.3 \%$ when using strict diagnostic criteria. Lwow et al. revealed that $70 \%$ of girls they examined admitted to dieting in the past or stayed on diet all the time [4]. Other studies indicate that over $25 \%$ of teenagers declare a desire of reducing their body weight, half of them reports overeating, $40 \%$ fears obesity, $28 \%$ disgusts food, and almost every tenth person provokes vomiting [5]. Anorexia is characterised by rapid organism devastation, and if untreated leads to death in about $10 \%$ of cases.
Persons suffering from anorexia also often report excessive irritability, insomnia, headaches and dizziness, tendency to fainting, also flatulences, constipations, hand freezing, excessive foot perspiration, hair loss, and a secondary amenorrhea or elongation of the period between menstruations. Eating disorders are also a risk factor of developing osteoporosis and osteopenia. Devastation, dry and pale skin, slowed down heart rate, low blood pressure are usually found during physical examination. Laboratory tests, besides anaemia, show also endocrine disturbance, especially in the scope of hypothalamic-pituitary axis, and disturbance of liver values.

Patients with eating disorders can simultaneously suffer from depression and present self-distructive behaviour (e.g. self-mutilation), and can be addicted to stimulants (alcohol, drugs) or to some activities (sex, shopping, physical activity). It is so because eating disorders are symptoms of patients current experiences (pain, stress, fear, loneliness, low self-esteem etc.). Such persons often do not understand the disorder's mechanisms and their behaviour (e.g. overeating and provoking vomiting) is of compulsive nature. Eating disorders require specialised treatment (psychologist, psychiatrist, psychotherapist, and sometimes nutritionist). Untreated eating disorders can lead to serious health complications, and even death. It is noteworthy that symptoms of eating disorders are not always noticeable to the attending physician because a lot of female patients use different ways in order to hide them and very often deny the disorder as well as occurrence of any difficulties.

\section{Diabulimia - eating disorders among patients with diabetes}

Manipulating insulin doses in order to control body weight is a eating problem that is more and more noticeable in patients with the type 1 diabetes. This phenomenon is called diabulimia. Diagnostic criteria of diabulimia are similar to those adopted by the Diagnostic and Statistical Manual (DSM) for diagnosing eating disorders in people without abnormal carbohydrate metabolism, that is for anorexia nervosa (AN), bulimia (BN), or Eating Disorders Not Otherwise Specified (EDNOS) [1]. These disorders, although differing in symptoms, have similar clinical features, from obsession concerning weight and body shape, to the cognitive distortion connected to perception of one's own body image [6]. The factor differentiating diabulimia from other entities included in the DSM-5 classification is intentional manipulation with insulin doses in order to obtain or maintain desired body weight. 
People suffering from type 1 diabetes are aware of people anabolic insulin action and consequence of using it in too high doses. They know that it can lead to weight gain. Patients with type 1 diabetes (DM1) and diabulimia omit insulin doses intentionally in order to reduce body weight or to prevent weight gain. Higher risk of this disorder is related to growing up girls and young women with type 1 diabetes. In comparison to healthy people, risk of developing eating disorders is higher in patients with diagnosed diabetes [7]. Diabulimia is not distinguished as a separate psychiatric entity in the current classifications (ICD-10 and DMS-5), however, already in 1970 first cases of patients with type 1 diabetes and accompanying eating disorders were described. Since then, the coexistence of type 1 diabetes and eating disorders have received more and more attention, especially in women [8].

Typical symptoms of diabulimia include: fast weight loss, lasting high values of glycaemia, high levels of glycated hemoglobin $\left(\mathrm{HbA}_{1 \mathrm{c}}\right)$, tendency to metabolic acidosis, improper eating habits usually similar to the diet of bulimics, and obsession with body shape and size and strong body dissatisfaction.

\section{Incidence}

Eating disorders can affect about $20 \%$ of women with type 1 diabetes [9]. Recent reports indicate that even $30 \%$ of adolescent girls with diabetes suffer from eating disorders [10]. Observational study of Colton et al. showed that $32.4 \%$ of young patients with type 1 diabetes met criteria of eating disorders, while in $8.5 \%$ of examined persons non-specific eating disorders were noted. Moreover, it was noted that in $60 \%$ of patients the disorder had begun even before they turned 25 years old. The average time between the disorder's onset and its remission was 4.3 years in the studied group. The average length of remission before the relapse was 6.5 year [11]. The problem of irregular behaviour in this area concerns only women with diabetes, however, incidence of this phenomenon also in men is more and more often emphasised [12]. Men, however, aim at reducing their weight not only through improper eating but, first of all, through intensive physical effort. Studies by Jones et al. showed that $12-40 \%$ of young women with diabetes admitted that they omitted insulin doses in order to reduce their body weight [10]. Similarly, other authors revealed that persons with diabetes are two times more prone to eating disorders than their contemporaries without the abnormal glucose tolerance [13]. Risk of suffering from eating disorders is especially high in youngsters with type 1 diabetes [14]. Higher susceptibility to their occurrence in the age of 12 and 19 years can result from: different intelligence levels, lack of understanding of the essence of the disease and its consequences, and also from psychological and sociological factors related to environmental priorities and risky behaviours related to the age. Studies also suggest that areas of frontal and parietal brain's lobes, responsible for planning and self-control, are not yet fully developed in younger teenagers, what can additionally influence their ability to comply with the treatment [15].

\section{Risk factors of developing eating disorders}

It is more and more often suggested to account the type 1 diabetes to the group of diseases with increased risk of developing eating disorders. Many authors also emphasise lowered susceptibility of tissues to insulin during puberty. This can lead to uncontrolled increase of insulin doses by persons with type 1 diabetes and in effect to significant gain of body weight, one of the most important risk factors of developing improper eating behaviour $[12,16]$. Jones et al. observed that omitting insulin doses was the most frequently used strategy to loose weight [10]. Takii et al. stresses that specificity of the disease itself can influence psychological risk of developing eating disorders [17]. Frequent phenomenon accompanying young people with diabetes is uncontrollable appetite resulting from episodes of hypoglicaemia and improper insulin dosage with simultaneous fear of gaining weight. In some patients, an important developmental element conductive to developing improper eating habits can also be the presence of strict diet plan forcing eating meals according to the set plan despite feeling hungry or full. Such phenomenon can lead to disturbance of self-regulation mechanism connected to feeling hungry or full [18]. Other risk factors connected to the specificity of diabetes also include: frequent controls of body weight, focusing on food, in particular precise carbohydrates counting and diet restrictions [19]. In persons predisposed to developing eating disorders of such type, they can constitute additional psychological burden and contribute to faster disclosure of improper eating patterns.

Beside social and cultural factors, also psychological behaviour predispose to the development of improper eating behaviour in type 1 diabetes, similarly to healthy persons. It is so because they are related to proper treatment of the disease in which focusing attention on the diet and body is a significant part of the treatment [20]. Additionally, problems can be intensified by physiological changes typical for puberty, often hindering reaching the state of good metabolic control [21]. Published literature points out that the pu- 
berty itself can be an essential risk factor of developing pathological eating patterns. In people with diabulimia, similarly to other eating disorders, dysmorphophobia can be observed (persistent conviction that the body is repulsive and worrying about the flaws of one's own appearance), as well as obsessive-compulsive disorders and anxiety disorders. Anxiety disorders can concern the insulin injections as well as the fear of hypoglycaemia. Not every person reducing the insulin is only body weight loss-oriented [22]. Caccavale et al. indicates significant influence of improper eating patterns of parents and their approach to dieting on developing improper eating habits [23].

Family environment and conflicts between its members play a vital role in the development of eating disorders in young people with diabetes [24]. Their appearance is often connected to difficult experiences that took place in the patient's life, e.g.: sexual exploitation, abuse, harassment (more frequently noticed in persons with bulimia than anorexia), physical and psychological violence, addictions or mental diseases in the family. Eating disorders are then a person's way of coping with trauma [25]. Coexistence of improper eating patterns with some personality disorders (borderline, obsessive-compulsive, histrionic) is also noteworthy.

\section{Warning signals of diabulimia}

Diagnosis is the most difficult process in the clinical practice, thus making the decision on treating the diabulimia - disorder not only of medical but also psychological nature. It is suggested that in this field prophylactic programs aimed at children 10-13 years old (similarly to children that do not have diabetes) are the most effective. Their intention should be making it impossible to create improper eating patterns and not permitting manipulation with insulin doses.

Moreover, one need to pay attention to any warning signals in a patient during the visit in the out-patients' clinic. The following should incline to suspect a patient with diabetes of eating disorder: high values of $\mathrm{HbA}_{1 \mathrm{c}^{\prime}}$ returning episodes of diabetic ketoacidosis, low BMI value, and low levels of body fat. It is also considered that such signal should include changes in patients behaviour, such as: rescheduling or omitting appointments in the clinic, not keeping the self-control journal, omitting or lowering the insulin doses, excessive concentration on precise counting and lowering the number of carbohydrate exchanges (often also calories), noticeable self concentration on the own appearance, high level of concentration on food and associated actions, using alternative diets (e.g. vegetarian, vegan, gluten elimination without medical recommendations, protein diet), very high level of physical activity. Mood changes are also frequently noticed in those patients, i.e. bad mood, depression, apathy, unwillingness to perform usual everyday activities, tiredness, mood swings, demanding too much of oneself, excessive meticulousness and conscientiousness, controlling tendencies.

In unclear situations, the following questions can be helpful:

- why does the patient is not able to obtain proper glycaemia control for a long time despite having good level of knowledge?

- is the patient's body weight too low or on the border of standards?

- in women: is she menstruating regularly?

- were there any other irregularities found in the test results (low haemoglobin content, high cholesterol concentration, electrolytes abnormalities)?

- is the patient concentrated on her appearance?

- is she manipulating with insulin doses for undisclosed reasons?

- is the patient highly concentrated on healthy eating and diets?

- has the patient mentioned any family difficulties (conflicts, disturbed relations or other psychological issues)?

- is the patient afraid of weighing or anthropomorphic measures (WHR)?

\section{Health consequences of diabulimia}

Manipulating insulin doses while controlling weight is particularly important due to its further clinical consequences. Numerous scientific reports confirm positive correlation of high $\mathrm{HbA}_{1 \mathrm{c}}$ values and eating disorders among persons with type 1 diabetes [26-28]. Whereas lack of metabolic balance of diabetes is a basic risk factor for developing many chronic complications of diabetes. It was noted that microangiopathic complications occurred significantly more frequently in people with diabulimia, especially retinopathy and returning episodes of diabetic ketoacidosis [29]. Takii et al. observed retinopathy in as much as $84 \%$ persons with diagnosed diabulimia [30]. Other studies indicated connection between eating disorders and not only retinopathy but also diabetic nephropathy [26]. 11-year observation showed 3-fold increase of the risk of death in a group of persons reducing insulin doses, when taking into consideration the age and $\mathrm{BMI}$ and $\mathrm{HbA}_{1 \mathrm{c}}$ values [31].

Diabulimia has not been formally recognised as a disease entity. So, explicit diagnostic criteria are lacking. That is why its identification is very difficult. On the other hand, influence of eating disorder on the 
short and long term health consequences for patients with diabetes has significant clinical relevance. Therefore, it is extremely important for medical personnel to be able to identify diabulimia warning signals as fast as possible, and to recognise risk factors that can lead to its development. Only this way it will be possible to properly support persons suffering from this problem. Confirmation of diabulimia by members of a therapeutic team is the key element of its treatment. In last two decades, a lot of research led to increasing the knowledge in this field [26, 32].

\section{Forms of treatment}

Treatment strategies for diabullimia are the same as those for treating eating disorders in the entire population. Applied forms of therapy include: psychotherapy, pharmacological treatment and hospitalisation. Usually, psychotherapy in diabulimia is in the form of individual, group or family therapy [31]. The latter is especially recommended when the problem affects a child because it is essential in such cases to intervene in the entire family environment, and not only the patient. It must be stressed that therapeutic interventions in the entire family give better chance of changing pathological situation that probably enhances the symptoms. Moreover, including family in the therapeutic process prevents stigmatisation of a patient and helps to better cope with acute emotions experienced by person's family. Research show that family therapy proved effective in $40-50 \%$ of cases in making long term changes of patients' eating patterns [33]. Similarly, Lock et al. indicated higher effectiveness of family therapy in comparison to individual therapy [34]. In some cases, psychological treatment should be combined with pharmacotherapy that in cases of diabulimia is based on sedating medicines and antidepressants [18]. Also medications improving the appetite are often used although in the case of anorexia their low effectiveness is emphasised. In people with bulimia administering medications aims at decreasing frequency of eating attacks. In cases of significant nutritional deficiencies, supplementation with calcium and vitamin D3 is implemented, and in a situation of endocrine disruptions, hormonal medications are administered [35]. That is why it is extremely important to cooperate with a gynaecologist and endocrinologist. Advantages of therapy led on an outpatient basis is the possibility of implementing of new patterns connected to food in everyday life. It also allows to learn new healthy eating patterns in one's own environment, and not in isolated place. Such form of therapy also enables observing changes in patient's social environment and makes adaptation to new reality easier. To obtain favourable effects of treatment on an outpatient basis it is necessary to include patient's family as an element of the therapy and support system. Patient's declared willingness to cooperate and motivation, and somatic condition that is not life-threatening are also crucial.

In some cases, outpatient treatment can be prove insufficient and then hospitalisation in a specialist centre is necessary. Factors indicating absolute need of referring the patient to a hospital include: pathogenic family environment resistant to changes, medical threats resulting from low body weight, suicidal thoughts and intentions, addition to addiction to drugs or alcohol, complete refusal to eat, poor effects in an outpatient treatment, deterioration of patient's condition despite undertaken interventions [36].

Fundamental element of effective treatment is an interdisciplinary therapeutic team. Cooperation of psychotherapist and psychiatrist with diabetologist, nurse/diabetes educator and nutritionist is crucial. Only this way patient's improvement can be made possible concerning metabolic balance of diabetes, monitoring therapy progress as well as control of the changing demand for insulin during changes in body weight and control of patient's behaviour related to food. With the altering weight, patient's daily energy intake is modified. That is why nutritionist's monitoring of daily menu and free increase in its energy value are significant [18].

\section{Summary}

Suspecting behaviour related to omitting an insulin doses as well as factors predisposing to development of eating disorders should evoke prompt and effective reaction. It is important because only an early and proper interventions can minimise the risk of developing complications in patients with type 1 diabetes.

Eating disorders, including diabulimia, appear as chronic disorders that represents complex relations between the disease, body, psyche, family, and society in the most clear manner. That is why treatment cannot be effective without knowing the rules of human development, family conditions and other social and cultural factors.

Guidelines for the attending physician:

1. It needs to be explained in details to the person suffering from diabulimia why proper administration of insulin is important.

2. Treatment plan preparation should be conducted in cooperation with the patient and his family, taking into consideration financial and organisational capability of the family. 
3. Guidelines concerning diet and insulin intake should be precise and easy to understand. Recommendations are the most effective when they are given in written form with patient's name and additional notes taking into consideration patient's individual needs.

4. Goals set for the patient should be easy to achieve. That is why, in order not to discourage the patient, one need to start from small changes in the diet and physical activity.

5. Persons with diabulimia often break rules set by physicians. The reason of that is strong fear as well as lack of understanding the recommendations. Moreover, such patients sometimes lack the courage to ask the physician for explanations or repeating the guidelines.

6. Frequent contact with the physician and other members of therapeutic team is necessary.

\section{REFERENCES}

1. American Psychiatric Association: Diagnostic and Statistical Manual of Mental Disorders. Fifth Edition. Arlington, VA, American Psychiatric Association, 2013.

2. Ziółkowska B (ed.). Opętane (nie)jedzeniem. Wydawnictwo Naukowe Scholar, Warszawa 2009.

3. Póżyński S, Wciórka J. Klasyfikacja zaburzeń psychicznych i zaburzeń zachowania w ICD-10. Opisy kliniczne i wskazówki diagnostyczne. Wydawnictwo Vesalius, Kraków 2000.

4. Lwow F, Dunajska K, Milewicz A, Występowanie czynników ryzyka jadłowstrętu psychicznego i bulimii u 18-letnich dziewcząt. Endokrynologia, Otyłość i Zaburzenia Przemiany Materii 2007; 3: 33-38.

5. Wojtyła A, Biliński P, Bojar I, Wojtyła C. Zaburzenia odżywiania u polskich gimnazjalistów. Prob Hig Epidemiol 2011; 92: 343-350.

6. Murphy R, Straebler S, Cooper Z, Fairburn CG. cognitive behavioral therapy for eating disorders. Psychiatric Clinics of North America 2010; 33: 611-627.

7. Jaffa T, McDermott B. Eating disorders in children and adolescents. Cambridge University Press, Cambridge 2006: 177-178.

8. Shaban C. Diabulimia: mental health condition or media hyperbole? Practical Diabetes 2013; 30: 104a-105a.

9. Markowitz J, Butler DA, Volkening LK et al. Brief screening tool for disordered eating in diabetes: Internal consistency and external validity in a contemporary sample of paediatric patients with type 1 diabetes. Diabetes Care 2010; 33: 495-500.

10. Jones JM, Lawson ML, Daneman D, Olmsted MP, Rodin G. Eating disorders in adolescent females with and without type 1 diabetes: cross sectional study. British Medical Journal 2000; 10: 1563-1566.

11. Colton PA, Olmsted MP, Daneman D et al. Eating disorders in girls and women with type 1 diabetes: a longitudinal study of prevalence, onset, remission, and recurrence. Diabetes Care 2015; 38: $1212-1217$

12. Neumark-Sztainer D, Patterson J, Mellin A, Ackard DM. Weight control practices and disordered eating behaviours among adolescent females and males with type 1 diabetes: association with socio-demographics, weight concerns. Diabetes Care 2002; 25: 1289-1296.

13. Smith FM, Latchford GJ, Hall RM, Dickson RA. Do chronic medical conditions increase the risk of eating disorder? A cross-sectional investigation of eating pathology In adolescent females with scoliosis and diabetes. Journal of Adolescent Health 2008; 42: 58-63.

14. Colton P, Rodin G, Bergenstal R, Parkin C. Eating disorders and diabetes: introduction and overview. Diabetes Spectrum 2009; 22: 138-142.
15. Court JM, Cameron FJ, Berg-Kelly K, Swift PG. Diabetes in adolescence. Pediatric Diabetes 2009; 10: 185-194.

16. Russell-Jones D \& Khan R. Insulin-associated weight gain in diabetes - causes, effects and coping strategies. Diabetes, Obesity and Metabolism 2007; 9: 799-812.

17. Takii M, Uchigata $Y$, Kishimoto J et al. The relationship between the age of onset of type 1 diabetes and the subsequent development of a severe heating disorder by female patients. Paediatric Diabetes 2011 ; 12: 396-401.

18. Larrañaga A, Docet MF, García-Mayor RV. Disordered eating behaviors in type 1 diabetic patients. World J Diabetes 2011; 15: 189-195.

19. Frank MR. Psychological issues in the care of children and adolescents with type 1 diabetes. Paediatric Child Health 2005; 10: 18-20.

20. Logan-Stotland N. Overcoming psychological barriers in insulin therapy. Insulin 2006; 1: 38-45.

21. Jacqueminet S, Massebœuf N, Rolland M, Grimaldi A, Sachon C. Limitations of the so-called "intensified" insulin therapy in type 1 diabetes mellitus. Diabetes and Metabolism 2005; 4: 4S45-44S50.

22. Bienvenu OJ, Samuels JF, Wuyek LA et al. Is obsessive-compulsive disorder an anxiety disorder, and what, if any, are spectrum conditions? A family study perspective. Psychol Med 2012; 42: 1-13.

23. Caccavale U, Nansel TR, Quick V, Lipsky LM, Laffel LM, Mehta SN. Associations of disordered eating behavior with the family diabetes environment in adolescents with type 1 diabetes. J Dev Behav Pediatr 2015; 36: 8-13.

24. Odgen J. Psychologia odżywiania się: od zdrowych do zaburzonych zachowań żywieniowych. Wydawnictwo Uniwersytetu Jagiellońskiego, Kraków 2011.

25. Haines J, Kleinman KP, Rifas-Shiman SL et al. Examination of shared risk and protective factors for overweight and disordered eating among adolescents. Archives of Pediatric Adolescent Medicine 2010; 164: 336-343.

26. Rydall AC, Rodin GM, Olmsted MP, Devenyi RG, Daneman D. Disordered eating behavior and microvascular complications in young women with insulin-dependent diabetes mellitus. N Engl J Med 1997; 336: 1849-1854.

27. Affenito SG, Adams CH. Are eating disorders more prevalent in females with type 1 diabetes mellitus when the impact of insulin omission is considered? Nutr Rev 2001; 59: 179-182.

28. Figueroa Sobrero A, Evangelista P, Mazza C et al. Three-year follow up of metabolic control in adolescents with type 1 diabetes with and without eating disorders. Arch Argent Pediatr 2010; 108: 130-135.

29. Wolfsdorf J, Craig ME, Daneman D et al. ISPAD Clinical Practice Consensus Guidelines 2006-2007. Diabetic ketoacidosis. Pediatr Diabetes 2007; 8: 28-43.

30. Takii M, Uchigata $Y$, Tokunaga $S$ et al. The duration of severe insulin omission is the factor most closely associated with the microvascular complications of type 1 diabetic females with clinical eating disorders. Int J Eating Disorders 2008; 41: 259-264.

31. Goebel-Fabbri AE, Fikkan J, Franko DL, Pearson K, Anderson BJ, Weinger $\mathrm{K}$. Insulin restriction and associated morbidity and mortality in women with type 1 diabetes. Diabetes Care 2008; 31: 415-419.

32. Hasken J, Kresl L, Nydegger T, Temme M. Diabulimia and the role of the school health personnel. Journal of School Health. 2010; 80: 465-469.

33. Wilson GT. Treatment of bulimia nervosa: When CBT fails. Behav Res Ther 1996; 34: 197-212.

34. Lock J, Le Grange D, Agras WS et al. Randomized clinical trial comparing family-based treatment with adolescent-focused individual therapy for adolescents with anorexia nervosa. Arch Gen Psychiatry 2010; 67:1025-1032.

35. Dobrzyńska E, Rymaszewska J, Jadłowstręt psychiczny - ciągłe wyzwanie dla współczesnej medycyny. Psychiatria w Praktyce Ogólnolekarskiej 2006; 6: 165-170.

36. Józefik B (ed.). Anoreksja i bulimia psychiczna: rozumienie i leczenie zaburzeń odżywiania się. Wydawnictwo Uniwersytetu Jagiellońskiego, Kraków 1999. 